\title{
Comparative Efficacy of a Biocompatible Citrate-Functionalized Magnetic Fluid Mediating Radiofrequency Hyperthermia and Magnetohyperthermia to Treat Ectopic Ehrlich-Solid-Tumor-Bearing Elderly Mice
}

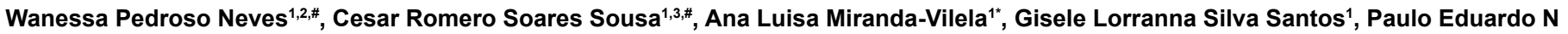
de Souza ${ }^{4}$, João Paulo Figueiró Longo ${ }^{1}$, and Zulmira Guerrero Marques Lacava ${ }^{1}$

${ }^{1}$ University of Brasilia, Campus Darcy Ribeiro, Institute of Biological Sciences, Brasilia, Brazil

${ }^{2}$ Faculty of Medicine, Integrated Faculties of the Planalto Central Educational Union (Faciplac), Campus Gama, DF, Brazil

${ }^{3}$ University Center of Brasília (UNICEUB), Brasilia, Brazil

${ }^{4}$ Institute of Physics University of Brasilia, Campus Darcy Ribeiro, Brasilia, Brazil

\#Contributed equally to this work

\begin{abstract}
Objective: We aimed to evaluate the efficacy of a biocompatible citrate-functionalized magnetic fluid (NPCit) sample in mediating hyperthermia, using two types of alternated (AC) magnetic field equipment operating in two different ways: a portable apparatus, generating an electromagnetic field in $\mathrm{MHz}$ range (radiofrequency range; radiofrequency hyperthermia-RFHT) developed by our research group (CMagMHG), and a commercial one working in $\mathrm{kHz}$ range (magnetohyperthermia-MHT) (Magnetherm, NanoTherics Ltd, Newcastle, United Kingdom), to treat ectopic Ehrlich-solid-tumor-bearing elderly mice.

Methods: Females intraperitoneally anesthetized with ketamine $(80 \mathrm{mg} / \mathrm{kg})$ and xylazine $(10 \mathrm{mg} / \mathrm{Kg})$ were subcutaneously inoculated with Ehrlich ascitic tumor cell suspension $\left(1.03 \times 10^{6}\right.$ viable cells $)$ in the upper head region for solid form implantation. After 48 hours, mice received one of four treatments: (a) filtered water and no tumor implantation (negative control); (b) tumor inoculation and no treatment (tumor control); (c) intratumoral injection of NPCit $(40 \mu \mathrm{L})$ containing $18 \times 10^{18}$ particles $/ \mathrm{mL}$ and 13 minutes' exposure to CMagMHG, operating at $1 \mathrm{MHz}, 40$ Oe field amplitude; (d) intratumoral injection of NPCit and 13 minutes' exposure to Magnetherm, assembled with 17-turn coil, capacitive box B22, operating under $330 \mathrm{kHz}, 4.9 \mathrm{~A}, 25 \mathrm{~V}$ and maximum field strength 170 Oe. Treatments occurred once daily for three consecutive days. Tumor histopathology and semi-quantitative analysis of necrosis area served to assess tumor aggressiveness and regression. Possible acute side effects were assessed by animals' body and spleen weight and hemogram.
\end{abstract}

Results: NPcit showed adequate biocompatibility and was effective in mediating RFHT and MHT, which promoted significant increases in necrosis area using both equipment types.

Conclusion: Our findings evidence the potential use of NPcit mediating hyperthermia for future use as an adjuvant in breast cancer therapy.

Keywords: Breast cancer; Citrate-coated maghemite nanoparticles; Magnetohyperthermia; Experimental ectopic breast cancer animal model; Ehrlich tumor; Magnetic fluid

\section{Introduction}

Cancer is a important global public health problem [1,2], because the disease is the second leading cause of death in high-income countries (following cardiovascular diseases) and the third leading cause of death in low- and middle-income countries (following cardiovascular diseases and infectious and parasitic diseases) [3]. It accounts for more than six million deaths each year, representing more than $12 \%$ of all causes of death worldwide $[1,4]$; of these, more than $70 \%$ of all cancer deaths occur in low and middle-income countries, where the resources available for prevention, diagnosis and treatment are limited or nonexistent [5].

Regarding cancer prevalence, breast, lung, prostate, and colorectal cancers are considered to be the "big four" [6], accounting for about $60 \%$ of all cancer cases [7], and even with the discovery of several dozens of novel anticancer drugs (natural and synthetic), the mortality from solid tumor remains constant [8]. This is, in part, because anticancer drugs must gain access to all viable cells within solid tumors in sufficient concentrations to cause lethality [9], if treatment is to be effective. However, solid tumors have a complex microenvironment that includes malignant cells, several types of normal cells and an extracellular matrix [10], besides having a poorly formed blood vascular system with variable rates of blood flow and much larger intercapillary distances than those found in normal tissues [9]. At the same time, most anticancer chemotherapeutic agents act nonspecifically, damaging both malignant and normal cells [11,12], which entails acute and chronic adverse effects that can compromise treatment [13]. Furthermore, the use of a single chemotherapeutic antineoplastic drug may show some limitations such as the development of resistance, high toxicity and constraints on clinical procedures [14]; indeed,

${ }^{*}$ Corresponding authors: Ana Luisa Miranda-Vilela, Department of Genetics and Morphology, Institute of Biological Sciences, University of Brasília, Brasilia, Brazil, Tel: 556131073087; Fax: 556131072923; E-mail: mirandavilela@unb.br

Received March 21, 2017; Accepted April 04, 2017; Published April 10, 2017

Citation: Neves WP, Soares Sousa CR, Miranda-Vilela AL, Silva Santos GL, de Souza PEN, et al. (2017) Comparative Efficacy of a Biocompatible CitrateFunctionalized Magnetic Fluid Mediating Radiofrequency Hyperthermia and Magnetohyperthermia to Treat Ectopic Ehrlich-Solid-Tumor-Bearing Elderly Mice. J Cancer Sci Ther 9: 393-392. doi: 10.4172/1948-5956.1000448

Copyright: (c) 2017 Neves WP, et al. This is an open-access article distributed under the terms of the Creative Commons Attribution License, which permits unrestricted use, distribution, and reproduction in any medium, provided the original author and source are credited. 
Citation: Neves WP, Soares Sousa CR, Miranda-Vilela AL, Silva Santos GL, de Souza PEN, et al. (2017) Comparative Efficacy of a Biocompatible Citrate-Functionalized Magnetic Fluid Mediating Radiofrequency Hyperthermia and Magnetohyperthermia to Treat Ectopic Ehrlich-SolidTumor-Bearing Elderly Mice. J Cancer Sci Ther 9: 393-392. doi: 10.4172/1948-5956.1000448

conventional antineoplastic chemotherapy has shown low efficiency when the disease is not treated in its early stages $[11,12]$.

In this context, research has endeavored to propose new alternatives and, among them, nanobiotechnology approaches and in particular the use of magnetic nanoparticles (MNPs) have emerged as promising and innovative ways to produce important advances in cancer therapy, such as magnetohyperthermia or magnetic hyperthermia [15]. Biocompatible MNPs coated with biodegradable polymers or molecules may generate heat when submitted to an external alternating current magnetic field, and their use is of interest because they especially target the tumoral tissue, since this is less resistant to sudden increases in temperature than the surrounding normal cells [15-19]. The application of hyperthermia has shown promise as a therapy against cancer [20], and it has been used to enhance the effectiveness of chemotherapy and radiotherapy [21]. This fact could be explained, at least in part, because cells in the S phase of the cell cycle are relatively resistant to radiation, while being sensitive to the increase in temperature. Hyperthermia represents an effective agent for cell destruction, especially for those cells in hypoxia, in need of nutrients and that are in a low $\mathrm{pH}$ environment, characteristics commonly present in malignant tumors [22]. Numerous clinical applications with tissue heating have been identified, including reduction in pain or inflammation and preservation of organs [23].

This pilot study aimed to compare the efficacy of a biocompatible citrate-functionalized magnetic fluid (NPCit) sample in mediating hyperthermia using two types of alternated (AC) magnetic field equipment operating in two different ways: a portable apparatus, generating an electromagnetic field in $\mathrm{MHz}$ range (radiofrequency range; radiofrequency hyperthermia-RFHT) developed by our research group (CMagMHG), and a commercial one working in $\mathrm{kHz}$ range (magnetohyperthermia-MHT) (Magnetherm, NanoTherics Ltd, Newcastle, United Kingdom), to treat ectopic Ehrlich-solid-tumorbearing elderly mice.

\section{Materials and Methods}

\section{Magnetic fluids}

To obtain the citrate-functionalized magnetic fluid (NPCit), nanoparticles of magnetite were synthesized by co-precipitation of $\mathrm{Fe}$ (II) and $\mathrm{Fe}$ (III) in alkaline medium, oxidized to maghemite $\left(\gamma-\mathrm{Fe}_{2} \mathrm{O}_{3}\right)$ [24], and then stabilized by citrate. The $\mathrm{pH}$ was adjusted to 7.0 and the salinity to $0.9 \%$ to promote biocompatibility $[25,26]$.

With the aim of determining structure and nanoparticle size, we performed X-ray power diffraction (XRD) using a Shimadzu diffractometer model DOX-6000 with copper $\mathrm{CuK} \alpha$ radiation, $\lambda=1.54$ Angstrom at $40 \mathrm{kV}$ and $20 \mathrm{~mA}$. For this, the sample was dehydrated in a low vacuum environment and stored as a powder without atmospheric contact; using a Zetasizer (Zetasizer Nano-ZS90 Malvern Instruments Limited, Malvern, UK) we determined the hydrodynamic radius, the polydispersion index and its surface charge by dynamic light scattering (DLS) with the sample diluted in ultra-pure deionized water (1: 100), and the measurements were performed in triplicate at $25^{\circ} \mathrm{C}$, with a fixed detection angle of $173^{\circ} \mathrm{C}$; the physical mean diameter and its dispersion was determined by transmission electron microscopy (TEM) performed on a JEOL 1011 (JEOL USA, Inc.) with sample diluted in ultra-pure deionized water (1:500), deposited in a 300 mesh copper TEM grid supported by films of Formvar, dried at room temperature for 24 hours and then counterstained for 45 minutes with $1 \%$ Osmium $\left(\mathrm{OsO}_{4}\right)$ vapor. The average diameter of the sample evaluated by MET was obtained by computer analysis, using Image-ProPLus software version 5.1 .

\section{Hyperthermia equipment}

To induce hyperthermia, two types of equipment generating an AC magnetic field were used, operating in two different ways. The first way was by radiofrequency (RF) hyperthermia (RFHT) promoted by a portable apparatus developed by our research group, CMagMHG $[27,28]$, operating at $1 \mathrm{MHz}$ with 40 Oe of field amplitude, constituted by one cylindrical metallic rod with $10.7 \mathrm{~mm}$ diameter closely wound by a coil of wire concentrating the alternating magnetic flux. The solenoid core is linked to a moveable support to apply the magnetic field in the targeted region (Figures $1 \mathrm{~A}$ and $1 \mathrm{~B}$ ). The equipment has an oscillating electric circuit with power integrator that generates an alternating electric current at high frequency, and a solenoid at the end of the movable rod with metal core, which concentrates the electromagnetic field of high frequency generated by the apparatus. At frequencies of the order of $\mathrm{MHz}$, the energy transferred to the nanoparticles promotes heating by Joule effect resulting from eddy currents induced at the interface of the nanoparticles with the liquid medium [29]. The second way to induce hyperthermia was using a commercial piece of equipment, Magnetherm (NanoTherics Ltd, Newcastle, United Kingdom) [30], assembled with 17-turn coil, capacitive box B22, operating under 330 $\mathrm{kHz}, 4.9 \mathrm{~A}, 25 \mathrm{~V}$ and maximum field strength of $170 \mathrm{Oe}$. In this device, the animal is introduced inside the coil, keeping it aligned with the coil's main axis (Figure 1C). When subjected to alternating magnetic fields in $\mathrm{kHz}$ range, superparamagnetic nanoparticles are heated by the rotation process of the magnetic moment in two conditions, together with the particle in the process, known as Brown rotation, or by the internal rotation independent of the magnetic moment, in what is termed the Neel rotation process. These processes dissipate heat and promote magnetohyperthermia (MHT) [31].

\section{In vivo tests}

Ehrlich tumor: The Ehrlich ascitic tumor was maintained in ascitic form by passages in Swiss mice, by weekly intraperitoneal transplantation of $10^{6}$ tumor cells [32]. The ascitic fluid, collected by intraperitoneal puncture, was counted in a Neubauer hemocytometer, and the Trypan blue dye exclusion method was used to evaluate the viable cells [33].

\section{Animals and experimental design}

Elderly female Swiss albino mice, 10-11 months, obtained from the Multidisciplinary Center for Biological Investigation in Laboratory Animal Science (CEMIB) of the State University of Campinas (Unicamp, SP/Brazil), were initially housed in plastic cages (6 animals/ cage) at room temperature $\left(22^{\circ} \mathrm{C} \pm 2^{\circ} \mathrm{C}\right)$ in a $12 \mathrm{~h}$ light/dark cycle with lights on at 6 a.m. and free access to food and water.

After being acclimatized to laboratory conditions for two weeks, animals, weighing $45.6 \mathrm{~g} \pm 5.47 \mathrm{~g}$ at the beginning of the experiment, were randomly distributed in the treatment and control groups $(\mathrm{N}=3$ / group), following the guidelines for the design and statistical analysis of experiments using laboratory animals for a pilot study [34], according to the recommendations of the international practices for animal use and care, and the Animal Ethics Committee of the Institute of Biological Sciences of the University of Brasilia/Brazil. For the xenograft, animals were intraperitoneally anesthetized with ketamine $(80 \mathrm{mg} / \mathrm{kg})$ and xylazine $(10 \mathrm{mg} / \mathrm{Kg})$ and subcutaneously inoculated with $40 \mu \mathrm{L}$ of previously frozen Ehrlich ascitic tumor cell suspension containing $1.03 \times 10^{6}$ viable cells, in the upper region of the head for solid form 
Citation: Neves WP, Soares Sousa CR, Miranda-Vilela AL, Silva Santos GL, de Souza PEN, et al. (2017) Comparative Efficacy of a Biocompatible Citrate-Functionalized Magnetic Fluid Mediating Radiofrequency Hyperthermia and Magnetohyperthermia to Treat Ectopic Ehrlich-SolidTumor-Bearing Elderly Mice. J Cancer Sci Ther 9: 393-392. doi: 10.4172/1948-5956.1000448
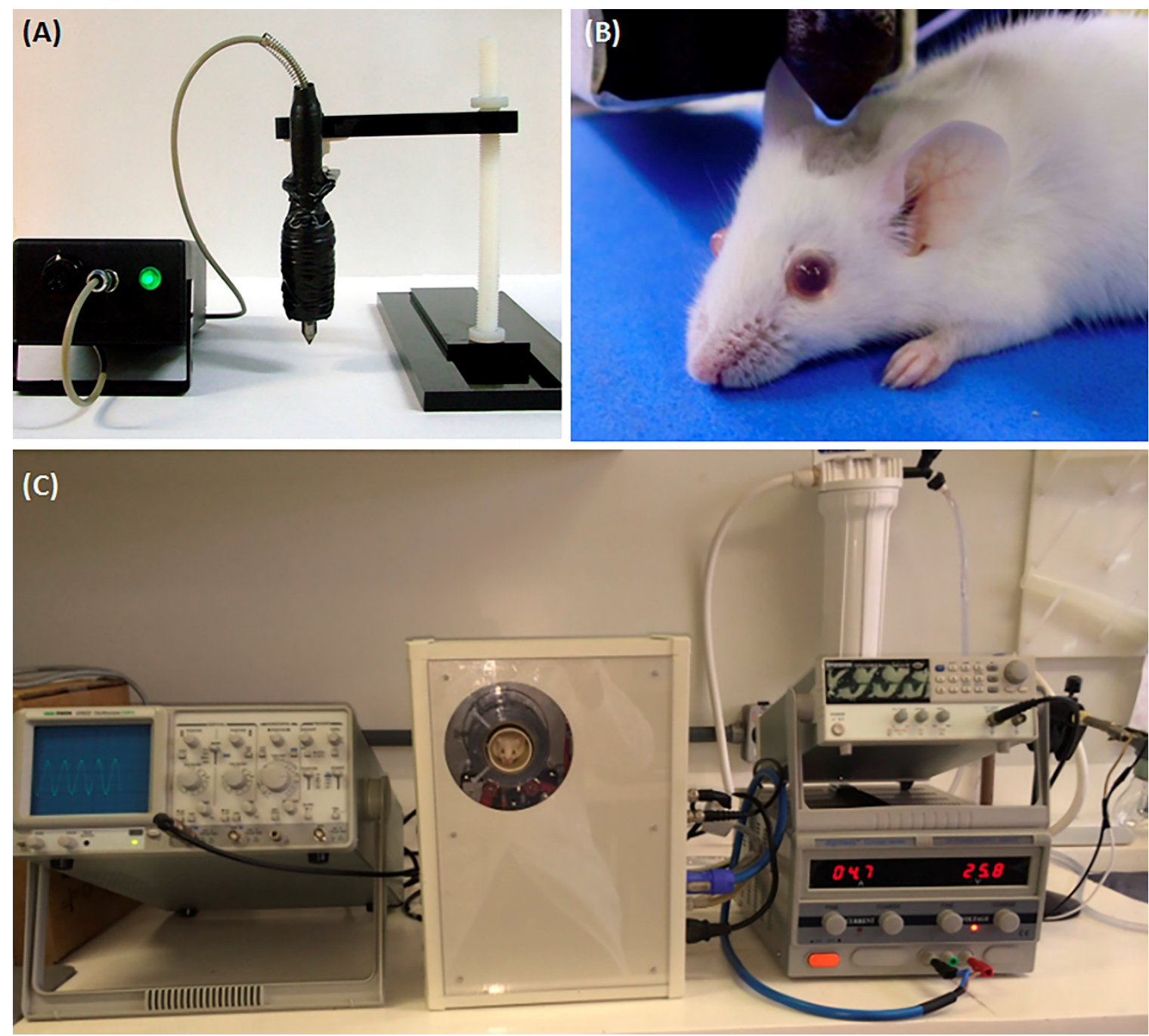

Figure 1: The alternated (AC) magnetic field equipment employed. (A) a portable apparatus developed by our research group (CMagMHG); (B) Detail of the animal under AC magnetic field (CMagMHG); (C) a commercial AC field product (Magnetherm, NanoTherics Ltd, Newcastle, United Kingdom).

implantation [15,32,35,36]. Following 48 hours after xenograft, all mice had clinical tumor and received the following treatments: (a) filtered water and non-tumor-bearing mice (negative control); (b) xenograft and no treatment (tumor control); (c) intratumoral injection of NPCit $(40 \mu \mathrm{L})$ containing $18 \times 10^{18}$ particles $/ \mathrm{mL}$ and exposure for 13 minutes to CMagMHG; (d) intratumoral injection of NPCit and exposure for 13 minutes to Magnetherm. Treatments were performed once a day for three consecutive days $[15,19,35]$. Body weights were measured at the beginning and end of the treatment, and the animals were monitored for signs of toxicity such as weight loss, diarrhea, skin ulcers and deaths.

Twenty-four hours after the last treatment, mice were anesthetized with ketamine and xylazine according to the method described above. Blood samples $(400 \mu \mathrm{L})$ collected by cardiac puncture were used to carry out hemogram in a multiple automated hematology analyzer for veterinary use, Sysmex pocH-100iV Diff (Curitiba/Paraná, Brazil) calibrated for mice in microtubes containing EDTA as anticoagulant. Euthanasia of the animals was carried out by cervical dislocation according to the Guidelines on Euthanasia of the federal council of veterinary medicine (CFMV) [37]. Tumors and spleens were surgically removed and weighed, the tumors' width, length and thickness were measured using a digital pachymeter, and their volume was calculated according to Yanase et al. [38]. Thereafter, they were fixed with $10 \%$ formalin for $24 \mathrm{~h}$, transferred to $70 \%$ ethanol, embedded in paraffin using an automatic tissue processor (OMA DM-40, São Paulo, Brazil), cut to $5 \mu \mathrm{m}$ of thickness in a Leica RM2235 manual microtome (Leica Microsystems, Nussloch, Germany) and stained with HematoxilinEosin (H\&E) according to standard procedures, for histological analyses (light microscopy). For iron detection, Prussian Blue staining was performed by the Perl's method, followed by counterstaining with Nuclear Fast Red [39]. All histological sections were photographed with an MC 80 DX camera coupled to a Zeiss Axiophot light microscope. Tumor necrosis was evaluated using a semi-quantitative method. A semi-quantitative score (0-4: 0 for none, 4 for $100 \%$ of necrosis) was used to determine the extension of necrosis area. At least five images of each microscopy field (microscope 20x magnification) were analyzed in 5 different histological slides, with a total of 25 histological tumor fields analyzed for each experimental individual. 
Citation: Neves WP, Soares Sousa CR, Miranda-Vilela AL, Silva Santos GL, de Souza PEN, et al. (2017) Comparative Efficacy of a Biocompatible Citrate-Functionalized Magnetic Fluid Mediating Radiofrequency Hyperthermia and Magnetohyperthermia to Treat Ectopic Ehrlich-SolidTumor-Bearing Elderly Mice. J Cancer Sci Ther 9: 393-392. doi: 10.4172/1948-5956.1000448

Tumor volume, histopathology and semi-quantitative analysis of necrosis area were used to assess its aggressiveness and regression. Possible acute side effects were assessed by animals' body and spleen weight and hemogram.

All animal handling and procedures were carried out according to the international practices for animal use and care, and approved by the Animal Ethics Committee of the Institute of Biological Sciences of the University of Brasilia/Brazil, reference number 44783/2013.

\section{Statistical Analysis}

Statistical analysis was carried out using SPSS 17.0 or GraphPad Prism 5.0, and values of $\mathrm{p}<0.05$ were considered significant. The continuous variables were tested for normal distribution with ShapiroWilk. Possible differences among the groups were investigated through ANOVA or the Kruskal-Wallis test (data normally distributed), followed respectively by Tukey's or Dunn's Multiple Comparison Tests.

\section{Results}

\section{Physicochemical characterization of the citrate-functionalized magnetic fluid (NPCit)}

NPCit showed brown color, with iron concentration of $16.8 \mathrm{mg} /$ $\mathrm{mL}$ and estimated maghemite nanoparticle concentration of $18 \times 10^{18}$ particles/mL. Magnetic nanoparticles (MNPs) diameters measured by the three different techniques showed average size values of $8 \mathrm{~nm}$ (diameter of the crystalline structure) by X-ray diffraction (XDR); 14.28 (modal average diameter) by transmission electronic microscopy
(TEM); and $66.34 \mathrm{~nm}$ (hydrodynamic average diameter) by dynamic light scattering (DLS). The average polydispersion index (PDI) and surface charge measured by the zeta potential were 0.24 and $-42.1 \mathrm{mV}$, respectively (Figure 2 ).

\section{In vivo tests}

Tumor histopathology and measurements: Areas of viable tumor cells surrounding central areas of necrosis were seen in all experimental groups (Figures $3 \mathrm{~A}$ and $3 \mathrm{~B}$ ). In the treatments with hyperthermia, the presence of MNPs was observed in the tumor area (Figure 3C), as was phagocytosis of them (Figure 3D). NPcit showed adequate biocompatibility and was effective in mediating hyperthermia (RFHT and MHT), which promoted non-significant reductions in tumor volume but significant increases in necrosis area, using both types of equipment (Figures 3E and 3F).

Evaluation of the acute side effects: No significant differences were found in the animals' body and spleen weight between the groups, but there was a tendency to greater spleen weight with treatments with hyperthermia, mainly using MHT (Magnetherm equipament). Also, no skin ulceration, weight loss or evident alterations were found, indicating the good tolerance of mice to the treatments.

Regarding results of the hemogram, the only statistically significant difference observed was an increase of neutrophils+monocytes (\%) in both treatment groups, with RFHT (CMagMHG) and MHT (Magnetherm), compared to negative control (Table 1).

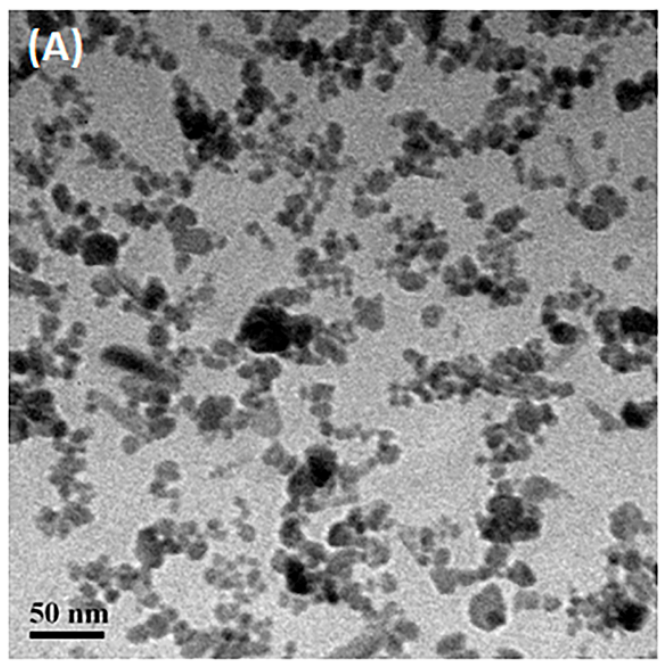

(C)

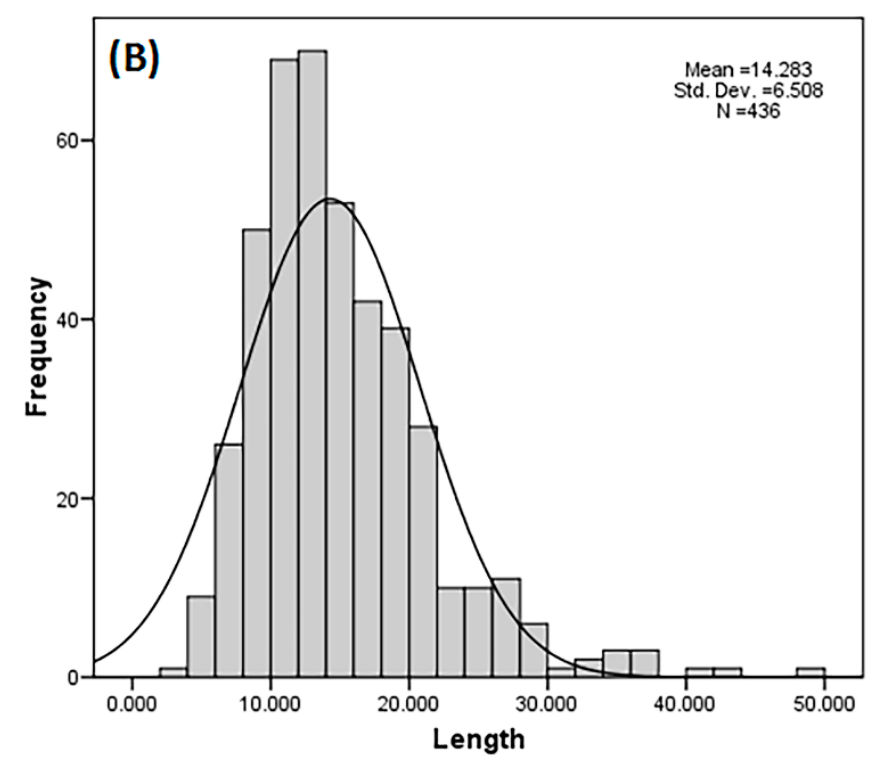

\begin{tabular}{|c|c|c|c|c|}
\hline $\mathbf{p H}$ & Color & $\begin{array}{c}\text { Hydrodynamic } \\
\text { diameter }(\mathbf{n m})\end{array}$ & PDI & Zeta Potential (mV) \\
\hline 7.0 & brown & $66.337 \pm 1.935$ & $0.236 \pm 0.018$ & $-42.100 \pm 1.386$ \\
\hline
\end{tabular}

Figure 2: Physicochemical characterization of the citrate-functionalized magnetic fluid (NPCit) by Transmission electron micrography (TEM) (A, B) and Zetasizer (C). Transmission electron micrograph (TEM) of citrate-coated magnetic nanoparticles (A) and the length-frequency distribution of the non-aggregated particles (B). $\mathrm{PDI}=$ polydispersion index; hydrodynamic diameter=diameter of the sample determined by dynamic light scattering (DLS); Zeta potential=surface charge measurement. 
Citation: Neves WP, Soares Sousa CR, Miranda-Vilela AL, Silva Santos GL, de Souza PEN, et al. (2017) Comparative Efficacy of a Biocompatible Citrate-Functionalized Magnetic Fluid Mediating Radiofrequency Hyperthermia and Magnetohyperthermia to Treat Ectopic Ehrlich-SolidTumor-Bearing Elderly Mice. J Cancer Sci Ther 9: 393-392. doi: 10.4172/1948-5956.1000448
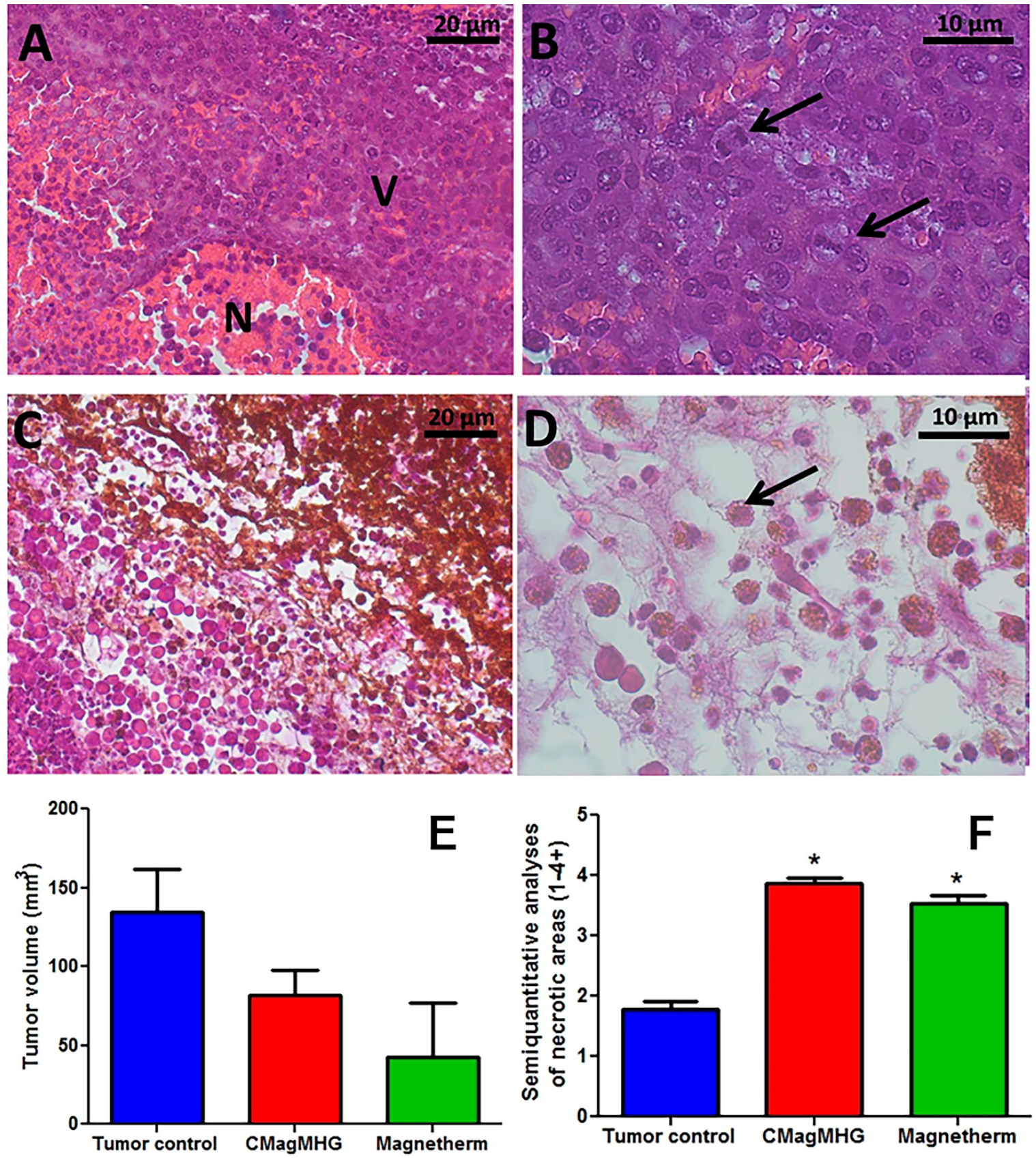

Figure 3: Tumor histopathology (A-D), tumor volume (E) and semi-quantitative analysis of the necrosis area (F). (A) and (B) viable tumor tissue with cells in mitosis (arrows). (C) and (D) necrotic tissue with MNPs being phagocytosed (arrow). $\mathrm{N}=$ necrosis area, $\mathrm{V}=$ viable area, MNPs=magnetic nanoparticles. (E) and (F) bar graphs were expressed as SEM (standard error of mean). Asterisks indicate significant differences $(p<0.001)$ compared to tumor control, detected by Dunn's Multiple Comparison Test.

\section{Discussion}

Nanometer-sized particles have attracted much attention, not only because of their unusual properties, but also due to their potential variety of applications in industry and in biomedical applications such as controlled drug delivery, nuclear magnetic resonance imaging agents, magnetic field guided drug transporters, tumor treatment via hyperthermia, magnetic biomolecular separation and diagnosis [4043]. Surface-functionalized superparamagnetic iron oxide nanoparticles
(SPIONs) are usually based on magnetite $\left(\mathrm{Fe}_{3} \mathrm{O}_{4}\right)$ or maghemite $\left(\gamma-\mathrm{Fe}_{2} \mathrm{O}_{3}\right)$ nanoparticles $[15,17,44,45]$, and represent a promising platform to build complex magnetic systems used for in vivo applications $[35,46]$. Since particle size and surface charge are important factors that determine their pharmacokinetics, toxicity and biodistribution [35,47], they must have adequate magnetic characteristics besides control in size and surface composition [43], because their physical characteristics can affect their in vivo performance $[35,47]$.

Nanoparticles (NPs) composed of ferromagnetic materials and with 
Citation: Neves WP, Soares Sousa CR, Miranda-Vilela AL, Silva Santos GL, de Souza PEN, et al. (2017) Comparative Efficacy of a Biocompatible Citrate-Functionalized Magnetic Fluid Mediating Radiofrequency Hyperthermia and Magnetohyperthermia to Treat Ectopic Ehrlich-SolidTumor-Bearing Elderly Mice. J Cancer Sci Ther 9: 393-392. doi: 10.4172/1948-5956.1000448

\begin{tabular}{|c|c|c|c|c|c|}
\hline & Negative control & Tumor control & CMagMHG & Magnetherm & p-value \\
\hline \multicolumn{6}{|l|}{ Erythrogram } \\
\hline $\operatorname{RBC}\left(\times 10^{6} / \mu \mathrm{L}\right)$ & $7.02 \pm 2.48$ & $9.12 \pm 0.35$ & $7.39 \pm 1.43$ & $8.71 \pm 0.32$ & 0.434 \\
\hline HGB (g/dL) & $9.98 \pm 3.55$ & $13.60 \pm 0.00$ & $10.77 \pm 1.79$ & $12.43 \pm 0.95$ & 0.344 \\
\hline HCT (\%) & $24.93 \pm 8.96$ & $33.80 \pm 1.70$ & $26.70 \pm 4.78$ & $33.57 \pm 3.90$ & 0.266 \\
\hline MCV (fL) & $35.50 \pm 0.74$ & $36.55 \pm 0.35$ & $36.20 \pm 0.62$ & $38.50 \pm 3.99$ & 0.353 \\
\hline $\mathrm{MCH}(\mathrm{pg})$ & $14.25 \pm 0.58$ & $14.70 \pm 0.85$ & $14.63 \pm 0.51$ & $14.30 \pm 0.61$ & 0.757 \\
\hline $\mathrm{MCHC}(\mathrm{g} / \mathrm{dL})$ & $40.18 \pm 0.90$ & $40.30 \pm 1.98$ & $40.40 \pm 0.95$ & $37.24 \pm 4.29$ & 0.360 \\
\hline RDW (\%) & $14.93 \pm 0.59$ & $14.15 \pm 0.21$ & $14.90 \pm 0.36$ & $14.70 \pm 0.26$ & 0.231 \\
\hline \multicolumn{6}{|l|}{ Leukogram } \\
\hline WBC $\left(\times 10^{3} / \mu \mathrm{L}\right)$ & $2.23 \pm 0.67$ & $2.25 \pm 1.20$ & $3.17 \pm 0.67$ & $2.53 \pm 0.90$ & 0.542 \\
\hline Lymphocytes (\%) & $52.97 \pm 12.65$ & $51.80 \pm 2.83$ & $34.37 \pm 7.31$ & $45.20 \pm 7.28$ & 0.129 \\
\hline Neutrophils+Monocytes (\%) & $35.73 \pm 6.04$ & $45.30 \pm 0.42$ & $62.97 \pm 7.31^{* \star a}$ & $52.97 \pm 6.23^{* a}$ & 0.005 \\
\hline Eosinophils (\%) & $3.40 \pm 3.11$ & $2.90 \pm 2.40$ & $2.67 \pm 1.04$ & $2.75 \pm 1.06$ & 0.977 \\
\hline \multicolumn{6}{|l|}{ Plateletgram } \\
\hline $\operatorname{PLT}\left(\times 10^{3} / \mu \mathrm{L}\right)$ & $1115.00 \pm 492.40$ & $1036.00 \pm 179.61$ & $969.67 \pm 240.56$ & $1250.67 \pm 164.93$ & 0.735 \\
\hline \multicolumn{6}{|c|}{$\begin{array}{l}\text { Data correspond to mean } \pm \text { standard deviation }(\mathrm{SD}) \text {. RBC=Red Blood Cells; HGB=Hemoglobin; HCT=Hematocrit; MCV=Mean Corpuscular Volume; MCH=Mear } \\
\text { Corpuscular hemoglobin; } \mathrm{MCHC}=\text { Mean corpuscular hemoglobin concentration; RDW=Red cell distribution width (represents an indication of the amount of variation } \\
\text { anisocytosis-in cell size); WBC=Total White Blood Cells; } \mathrm{PLT}=\text { platelet count; } \mathrm{MPV}=\text { mean platelet volume; } \mathrm{g} / \mathrm{dL}=\mathrm{grams} \text { per deciliter; } \mathrm{fl}=\mathrm{fentoliters;} \mathrm{pg}=\mathrm{picograms} \text {. P-value } \\
\text { were generated by ANOVA. The superscript letters indicate significant differences detected by the Tukey's post hoc test, with a=significant compared to negative control } \\
\text { Asterisks indicate significant differences at }{ }^{*} \mathrm{p}<0.05 \text { and }{ }^{* *} \mathrm{p}<0.01\end{array}$} \\
\hline
\end{tabular}

Table 1: Hemogram of healthy and Ehrlich-solid-tumor-bearing mice before and after treatments.

size $<10 \mathrm{~nm}$ to $20 \mathrm{~nm}$ exhibit an inimitable form of magnetism, i.e. super paramagnetism [45]. In this context, NPCit presented an adequate size and appeared to be physiologically well tolerated. Although diameters measured by the three different techniques showed different average size values, this was already expected. XDR is mainly used to know the crystalline phase of the nanoparticles (maghemite or magnetite) [48], confirming the composition of maghemite, which is the final step of magnetite oxidation and thus chemically more stable [15,49]. The comparison between XRD, TEM and DLS results confirmed that NPCit have a crystalline core and an amorphous external layer. However, due to the existence of barely-crystalline particles with an amorphous layer, the diameter measured by XRD was expected to be smaller than that measured by TEM, which, in turn, was expected to be smaller than that measured by DLS (the hydrodynamic diameter depends not only on the size of the particle "core", but also on any surface structure). Moreover, the NPCit sample with an average polydispersity index (PDI) of 0.236 indicated particles with a moderate polydisperse distribution.

The cytotoxicity of NPs depends, among other things, on surface charge; NPs with positive charges are more toxic than negatively charged particles $[35,50]$. NPs with zeta potentials greater than +30 $\mathrm{mV}$ or less than $-30 \mathrm{mV}$ are considered strongly cationic and anionic, respectively, while those with a zeta potential between -10 and +10 $\mathrm{mV}$ are considered approximately neutral. As most cell membranes are negatively charged, zeta potential may affect the tendency of a NP to permeate membranes, with cationic particles generally exhibiting more toxicity associated with cell wall rupture [51]. Based on the zeta potential result, we can suppose that the NPCit will maintain a negative surface charge in the physiological $\mathrm{pH}$, corroborating a previous suggestion that it appears to be physiologically well tolerated, besides being efficient in mediating hyperthermia in both types of equipment tested.

MNPs covered with biodegradable polymers or molecules can be heated by the application of an external AC magnetic field and are therefore capable of producing localized heating in a desired area $[18,19]$. In this context, NPcit showed adequate biocompatibility and was effective in mediating RFHT and MHT, which produced regression in tumor aggressiveness using both types of equipment, with virtually no adverse acute effects. Even though clinical tumor volume was non- significantly reduced with both treatments compared to non-treated tumor, results of tumor histology and morphometry indicated that this could be related to the release of tumor necrosis debris and the associated inflammatory process induced in tumors submitted to the experimental treatments. Although immunohistochemistry was not used to validate claims of defensive cell infiltration, the increased neutrophils+monocytes observed for both treatments, particularly with CMagMHG, corroborate this suggestion.

CMagMHG was developed in order to perform hyperthermia tests, when biological tests were conducted after exposing the peritoneal region of mice to the AC field. This work showed that the damage induced by the AC field to normal cells is related to the exposure time, and (2) the equipment developed is appropriate to perform hyperthermia experiments. Significant alterations of increased lymphocytes were observed, simultaneously with decreased monocyte frequency, when the peritoneum was exposed for 10 minutes, not observing alterations in the neutrophil frequency at any time after AC field exposure, an important signature of inflammatory reaction [28]. Although these results appear contradictory in respect to ours, this study was carried out with healthy animals [28], and the installation of the Ehrlich solid tumor by itself has been demonstrated by our group as non-significantly decreasing lymphocytes and significantly increasing neutrophils+monocytes [32], corroborating our results. Even if the 10 minutes of magnetic field exposure and treatments used were previously tested $[15,19,28,35]$ and have been chosen to be sufficient to induce hyperthermia with practically no hematological adverse effects, we opted in this present work to increase the exposure time to CMagMHG by three minutes (maximum time that the animals were anesthetized/asleep during exposure), in order to compare with the Magnetherm equipment, where the animals remain dormant until the end of the anesthesia.

In the Magnetherm the animal is introduced inside the coil, keeping it aligned with the coil's main axis, while in the CMagMHG the solenoid core is linked to a moveable support to apply the magnetic field to the targeted region. As a result, the observed tendency to greater spleen weight with magnetohyperthermia, mainly using Magnetherm, 
Citation: Neves WP, Soares Sousa CR, Miranda-Vilela AL, Silva Santos GL, de Souza PEN, et al. (2017) Comparative Efficacy of a Biocompatible Citrate-Functionalized Magnetic Fluid Mediating Radiofrequency Hyperthermia and Magnetohyperthermia to Treat Ectopic Ehrlich-SolidTumor-Bearing Elderly Mice. J Cancer Sci Ther 9: 393-392. doi: 10.4172/1948-5956.1000448

was already expected, since the animals are exposed as a whole to the magnetic field in Magnetherm, while in CMagMHG, the magnetic field was applied to the targeted region (tumor) (Supplementary Figure).

\section{Conclusion}

NPcit showed adequate biocompatibility and was effective in mediating RFHT and MHT, which promoted non-significant reductions in tumor volume but significant increases in necrosis area using both types of equipment. Our findings evidence the potential use of NPcit mediating hyperthermia for future use as an adjuvant in breast cancer therapy.

\section{Acknowledgements}

We are grateful to Prof ${ }^{a} \mathrm{Dr}^{\mathrm{a}}$ Emília Celma de Oliveira Lima of the Institute of Chemistry (IQ) of the Federal University of Goiânia (UFG) for the NPCit sample and the Brazilian National Council for Technological and Scientific Development (CNPq), the Foundation to Support Research in the Federal District (FAPDF), the Coordination for Further Training of Graduate Staff (CAPES), the CAPES-Network CON-NANO (CAPES), National Institute of Science and Technology in Nanobiotechnology (INCT-Nanobiotecnologia), Center for Nanoscience and Nanobiotechnology of the University of Brasilia (CNANO-UnB), and dean of research and postgraduation of the University of Brasilia (DPP-UnB) for financial support.

\section{References}

1. Guerra MR, Moura Gallo CV, Mendonça GAS (2005) Risk of cancer in Brazil: Trends and epidemiological studies. Rev Bras Cancerol 51: 227-234.

2. Siegel RL, Miller KD, Jemal A (2016) Cancer statistics. CA Cancer J Clin 66: 7-30.

3. American cancer society (2015) Global Cancer: Facts and figures. (3rdedn). Atlanta: American Cancer Society 1-61.

4. Jemal A, Bray F, Center MM, Ferlay J, Ward E, et al. (2011) Global cancer statistics. CA Cancer J Clin 61: 69-90.

5. Gavhane YN, Shete AS, Bhagat AK, Shinde VR, Bhong KK, et al. (2011) Solid tumors: Facts, challenges and solutions. Int J Pharma Sci Res 2: 1-12.

6. Rahib L, Smith BD, Aizenberg R, Rosenzweig AB, Fleshman JM, et al. (2014) Projecting cancer incidence and deaths to 2030. Cancer Res 74(14): 4006.

7. Butcher $L$ (2008) Solid tumors: Prevalence, economics, and implications for payers and purchasers. Biotechnol Health 5: 20-1.

8. El-Sayed MA, Shabaka AA, El-Shabrawy OA, Yassin NA, Mahmoud SS, et al. (2013) Tissue distribution and efficacy of gold nanorods coupled with laser induced photoplasmonic therapy in ehrlich carcinoma solid tumor model. PLoS One 8: e76207.

9. Tunggal JK, Cowan DS, Shaikh H, Tannock IF (1999) Penetration of anticancer drugs through solid tissue: a factor that limits the effectiveness of chemotherapy for solid tumors. Clin Cancer Res 5: 1583-1586.

10. Grantab RH, Tannock IF (2012) Penetration of anticancer drugs through tumour tissue as a function of cellular packing density and interstitial fluid pressure and its modification by bortezomib. BMC Cancer 12: 214.

11. Almeida VLd, Leitão A, Reina LdCB, Montanari CA, Donnici CL, et al. (2005) Cancer specific nonspecific cyclo-cell and cyclo-cellular antineoplastic agents that interact as DNA: an introduction. New Chemical 28: 118-129.

12. Carneiro MLB, Peixoto RCA, Joanitti GA, Oliveira RGS, Telles L, et al. (2013) Antitumor effect and toxicity of free rhodium (II) citrate and rhodium (II) citrateloaded maghemite nanoparticles in mice bearing breast cancer. J Nanotechnol 11: 4.

13. Ozben T (2007) Oxidative Stress and Apoptosis: Impact on Cancer Therapy. J Pharm Sci 96: 2181-2196.

14. Wang $\mathrm{H}$, Zhao $\mathrm{Y}, \mathrm{Wu} \mathrm{Y}, \mathrm{Hu} \mathrm{YL}$, Nan K, et al. (2011) Enhanced anti-tumor efficacy by codelivery of doxorubicin and paclitaxel with amphiphilic methoxy PEG-PLGA copolymer nanoparticles. Biomaterials 32: 8281-8290.

15. Miranda-Vilela AL, Peixoto RCA, Longo JPF, Cintra DdOS, Portilho FA, et al (2013) Dextran-Functionalized Magnetic Fluid Mediating Magnetohyperthermia Combined with Preventive Antioxidant Pequi-Oil Supplementation: Potential Use Against Cancer. J Biomed Nanotechnol 9: 1261-1271.
16. Berry CC, Curtis ASG (2003) Functionalisation of magnetic nanoparticles for applications in biomedicine. J Phys D: Appl Phys 36: R198-R206.

17. Tartaj P, Morales MP, Veintemillas-Verdaguer S, González-Carreño T, Serna CJ (2003) The preparation of magnetic nanoparticles for applications in biomedicine. J Phys D: Appl Phys 36: R182.

18. Chatterjee J, Bettge M, Haik Y, Jen Chen C (2005) Synthesis and characterization of polymer encapsulated $\mathrm{Cu}-\mathrm{Ni}$ magnetic nanoparticles for hyperthermia applications. J Magn Magn Mater 293: 303-309.

19. Portilho FA, Estevanato LLC, Miranda-Vilela AL, Almeida-Santos MFM, de Oliveira-Cavalcanti CE, et al. (2011) Investigation of a magnetohyperthermia system efficacy. J Appl Phys 109: 07B307.

20. Vasseur S, Duguet E, Portier J, Goglio G, Mornet S, et al. (2006) Lanthanum manganese perovskite nanoparticles as possible in vivo mediators for magnetic hyperthermia. J Magn Magn Mater 302: 315-320.

21. van der Zee J, González D, van Rhoon GC, van Dijk JDP, van Putten WLJ, et al (2000) Comparison of radiotherapy alone with radiotherapy plus hyperthermia in locally advanced pelvic tumours: a prospective, randomised, multicentre trial. Lancet 355: 1119-1125.

22. Aktas M, de Jong D, Nuyttens JJ, van der Zee J, Wielheesen DHM, et al (2007) Concomitant radiotherapy and hyperthermia for primary carcinoma of the vagina: A cohort study. Eur J Obstet Gynecol Reprod Biol 133: 100-104.

23. Stauffer PR (2005) Evolving technology for thermal therapy of cancer. Int J Hyperthermia 21: 731-744.

24. Kang YS, Risbud S, Rabolt JF, Stroeve $P(1996)$ Synthesis and characterization of nanometer-size $\mathrm{Fe}_{3} \mathrm{O}_{4}$ and $\mathrm{y}-\mathrm{Fe}_{2} \mathrm{O}_{3}$ Particles. Chem Mater 8: 2209-2211.

25. Morais PC, Santos RL, Pimenta ACM, Azevedo RB, Lima ECD (2006) Preparation and characterization of ultra-stable biocompatible magnetic fluids using citrate-coated cobalt ferrite nanoparticles. Thin Solid Films 515: 266-270.

26. da Silva SW, Melo TFO, Soler MAG, Lima ECD, da Silva MF, et al. (2003) Stability of citrate-coated magnetite and cobalt-ferrite nanoparticles under laser irradiation: a Raman spectroscopy investigation. IEEE Trans Magn 39: 2645 2647.

27. Guedes MHA, Lacava ZGM, Guedes MEA, da Silva MF, Morais PC (2002) Portable radio-frequency electromagnetic field generator. Brazil. PI0204433-1.

28. Guedes MHA, Guedes MEA, Morais PC, da Silva MF, Santos TS, et al. (2004) Proposal of amagnetohyperthermia system: preliminary biological tests. J Magn Magn Mater 272: 2406-2407.

29. Tamarov KP, Osminkina LA, Zinovyev SV, Maximova KA, Kargina JV, et al (2014) Radio frequency radiation-induced hyperthermia using Si nanoparticlebased sensitizers for mild cancer therapy. Sci Rep 4: 7034

30. Krishnan KM, Ferguson MR, Khandhar AP (2012) Tuned multifunctiona magnetic nanoparticles for biomedicine. In: University of Washington Center for Commercialization (Org.) Google Patent, USA.

31. Tasci TO, Vargel I, Arat A, Guzel E, Korkusuz P, et al. (2009) Focused RF hyperthermia using magnetic fluids., Med Phys 36: 1906-1912.

32. Miranda-Vilela AL, Portilho FA, de Araujo VG, Estevanato LL, Mezzomo BP, et al. (2011) The protective effects of nutritional antioxidant therapy on Ehrlich solid tumor-bearing mice depend on the type of antioxidant therapy chosen Histology, genotoxicity and hematology evaluations. J Nutr Biochem 22: 1091 1098.

33. Estevanato L, Cintra D, Baldini N, Portilho F, Barbosa L, et al. (2011) Preliminary biocompatibility investigation of magnetic albumin nanosphere designed as a potential versatile drug delivery system. Int J Nanomedicine 6: 1709-1717.

34. Festing MF, Altman DG (2002) Guidelines for the design and statistical analysis of experiments using laboratory animals. ILAR J 43: 244-258.

35. Miranda-Vilela A, Yamamoto K, Miranda K, Matos B, Almeida M, et al. (2013) Dextran functionalized magnetic fluid mediating magnetohyperthermia for treatment of Ehrlich-solid-tumor bearing mice: Toxicological and histopathological evaluations. Tumor Biol 35: 3391-403.

36. Miranda-Vilela AL, Grisolia CK, Longo JPF, Peixoto RCA, de Almeida MC, et al. (2014) Oil rich in carotenoids instead of vitamins $C$ and $E$ as a better option to reduce doxorubicin-induced damage to normal cells of Ehrlich tumor-bearing mice: hematological, toxicological and histopathological evaluations. J Nutr Biochem 25: 1161-1176. 
Citation: Neves WP, Soares Sousa CR, Miranda-Vilela AL, Silva Santos GL, de Souza PEN, et al. (2017) Comparative Efficacy of a Biocompatible Citrate-Functionalized Magnetic Fluid Mediating Radiofrequency Hyperthermia and Magnetohyperthermia to Treat Ectopic Ehrlich-SolidTumor-Bearing Elderly Mice. J Cancer Sci Ther 9: 393-392. doi: 10.4172/1948-5956.1000448

37. Conselho Federal de Medicina Veterinária (CFMV) (2013) Brazilian guide to good practices for euthanasia in animals: concepts and recommended procedures. Brasília/Brazil: Commission on Ethics, Bioethics and Anima Welfare/CFMV. P. 62

38. Yanase M, Shinkai M, Honda H, Wakabayashi T, Yoshida J, et al. (1998) Intracellular hyperthermia for cancer using magnetite cationic liposomes: an in vivo study. Jpn J Cancer Res 89: 463-469.

39. Millward JM, Schnorr J, Taupitz M, Wagner S, Wuerfel Jens T, et al. (2013) Iron oxide magnetic nanoparticles highlight early involvement of the choroid plexus in central nervous system inflammation. ASN Neuro 5: e00110.

40. Lacava LM, Lacava BM, Azevedo RB, Lacava ZGM, Buske N, et al. (2001) Nanoparticle sizing: Acomparative study using atomic force microscopy, transmission electron microscopy, and ferromagnetic resonance. J Magn Magn Mater 225: 79-83.

41. Torchilin VP (2014) Multifunctional, stimuli-sensitive nanoparticulate systems for drug delivery. Nat Rev Drug Discov 13: 813-827.

42. Long NV, Yang Y, Teranishi T, Thi CM, Cao Y, et al. (2015) Biomedical Applications of Advanced Multifunctional Magnetic Nanoparticles. J Nanosci Nanotechnol 15: 10091-10107.

43. Fontanive VCP, Khalil NM, Cotica LF, Mainardes RM (2014) Physical and biological aspects denanopartículas of magnetic ferrites. Rev Farm Basic Appl 35: $549-558$
44. Barbosa LS, Sadeghiani N, Guedes MHA, Oliveira DM, Tedesco AC, et al. (2006) Effects of magnetic field and magnetoliposomes on mice: Cytotoxicity and genotoxicity tests. IEEE Trans Magn 42: 3605-3607.

45. Ali A, Zafar H, Zia M, ul Haq I, Phull AR, et al. (2016) Synthesis, characterization applications, and challenges of iron oxide nanoparticles. Nanotechnol Sci Appl 9: 49-67.

46. Estevanato LL, Lacava LM, Carvalho LC, Azevedo RB, Silva O, et al. (2011) Long-term biodistribution and biocompatibility investigation of dextran-coated magnetite nanoparticle using mice as the animal model. J Biomed Nanotechnol 8: 301-308.

47. Berry CC (2009) Progress in functionalization of magnetic nanoparticles for applications in biomedicine. J Phys D: Appl Phys 42: 224003.

48. Mamani JB, Gamarra LF, Brito GEdS (2014) Synthesis and characterization of $\mathrm{Fe} 3 \mathrm{O} 4$ nanoparticles with perspectives in biomedical applications. Mat Res 17: 542-549.

49. Plaza RC, Arias JL, Espín M, Jiménez ML, Delgado AV (2002) Aging effects in the electrokinetics of colloidal iron oxides. J Colloid Interface Sci 245: 86-90.

50. Fröhlich E (2012) The role of surface charge in cellular uptake and cytotoxicity of medical nanoparticles. Int J Nanomedicine 7: 5577-5591.

51. Clogston JD, Patri AK (2011) Zeta potential measurement. Methods Mol Bio 697: 63-70. 